\title{
Male sexual disorders in patients with parkinson disease: treatment with natural remedies
}

\begin{abstract}
Parkinson's disease (PD) is a neurodegenerative disorder caused by a progressive deterioration of midbrain dopamine neurons in the substantia nigra. The incidence of $\mathrm{PD}$ in male is higher than that in women, but psychological symptoms are as varied as the motor symptoms in both gender. Psychological symptoms encompass a decrease in sexual desire with a long list of thymic, cognitive, behavioral, and neuropsychiatric complications. Their origin can be attributed to the natural course of the disease, side effects of treatment, or both. Clinical researches are mainly focused on the dominant motor symptoms of PD, but the nonmotor features of PD also need attention. Sexual dysfunctions (SD) are one of the most neglected nonmotor symptoms in PD. SD usually begin after the onset of motor disorders and many patients receiving DA agonists as treatment manifest uncontrollable sexual desire, playing thus a major role in the deterioration of the life's quality of patients and their partners. Research articles were retrieved from PubMed and Google using relevant keywords. Overall, this review emphasize on the sexual disorders widely reported in patients with PD and the types of natural products that are potential future supplementary agents in their control.
\end{abstract}

Volume 3 Issue 2 - 2017

\author{
Kameni Poumeni Mireille, Dzeufiet Djomeni \\ Paul Desire, Kamtchouing Pierre \\ Department of Animal Biology and Physiology, University of \\ Yaounde I, Cameroon
}

Correspondence: Kameni Poumeni Mireille, University of Yaounde I, PO BOX 8I 2, Yaounde, Cameroon, Tel +237 699288 365, Email kameni@uyl.uninet.cm

Received: August 25, 2017 | Published: November 24, 2017

Keywords: hyper sexuality, erectile dysfunction, plants, aphrodisiac, neuroprotective

Abbreviations: PD, parkinson's disease; ED, erectile dysfunction; HS, hypersexuality; NADH, nicotinamide adenine dinucleotide; 6-OHDA, 6-hydroxydopamine; MPTP, 1,2,3,6-methyl-phenyl-tetrahydropyridine; MAO, monoamine oxidase

\section{Introduction}

Parkinson's disease (PD) is a common neurodegenerative movement disorder characterized by extensive degeneration of dopamine (DA) neurons in the nigrostriatal system. ${ }^{1}$ It is the second most common human neurodegenerative disorder after Alzheimer's disease and is characterized by progressive motor disability and cognitive dysfunction., ${ }^{2,3}$ PD inflicts a tremendous social and economic burden on modern society due to its disabling nature and high prevalence in the aging population. Currently, the mean age of onset is around 55 years. ${ }^{4}$

Clinical studies support that the incidence of PD in male is higher than that in women, ${ }^{5}$ but psychological symptoms are as varied as the motor symptoms in both gender. Autonomic dysfunction symptoms significantly impair the quality of life of PD patients, even more than motor symptoms. ${ }^{6}$ Autonomic dysfunctions are part of a spectrum of non-motor symptoms in patients with PD. ${ }^{7}$ Nonmotor symptoms may precede typical motor features of PD by several years. ${ }^{8,9}$ The spectrum of nonmotor symptoms encompasses constipation, bladder dysfunction, daytime somnolence, delusions/hallucinations, difficulty in concentration, dribbling, dysphagia, episodes of confusion, fatigue, impulse control disorders, memory problems, mood disorders (depression, anxiety), orthostatic hypotension, pain, paranoia, sensation of breathlessness, sleep disturbances, sweating, and also sexual disorders. ${ }^{10,11}$

The conventional strategies of PD treatment are oriented towards increasing the level of the striatal DA; this is achieved either by increasing the DA precursor (levodopa) supply or by inhibiting the DA breakdown by monoamine oxidase (MAO). ${ }^{12}$ However, the therapeutic dose of levodopa is adapted to the neuronal degeneration progresses, leading thus to an increasing demand of Levodopa administration. ${ }^{13}$ The resulting insatiable supply of DA is linked to many undesirable side effects, which compromise the benefits and limit of the medical treatment. According to Bhattacharyya et al., ${ }^{14}$ the extent of the DA agonist side effects especially on sexual function is still one of the most under recognized aspects of the condition after 200 years since the very first description by James Parkinson. The focus of management is the relief of the clinically dominant motor symptoms of PD, but the non-motor features of PD also need attention. ${ }^{12}$ In particular, sexual disorders (SD), those are commonly reported in patients with $\mathrm{PD}^{15,16}$ and have attracted attention since the important publication of Giovannoni et al. ${ }^{17}$ The incidence of SD related to the increasing use of DA medication ${ }^{18}$ has been explained by the main role of DA in sexual function. DA is a key neurotransmitter in the control of sexual functions, potentially involved in both sexual motivation and control of sexual performance. ${ }^{19}$

In recent years, novel therapeutic approaches are being investigated with the intention of influencing pathways leading to hinder or alleviate PD symptoms. Some active compounds derived from plants have been found to exert neuroprotective, aphrodisiac and/or an aphrodisiac effect in PD animal models, raising the possibility that natural products may be an effective therapeutic strategy to alleviate DA agonist side effects. The aim of this review is to report on the impact of PD and its treatment on male sexuality, on the available antiParkinson agents based on natural products, and also to sum up their therapeutic actions acting on various pathways. Overall, this review emphasize on the types of natural products that are potential future supplementary agents in the control of sexual disorders associated to PD.

\section{Discussion}

\section{Sexual disorders: parkinson's disease or physiological nature?}

In patients with $\mathrm{PD}$, sexual disorders usually begin after the onset 
of motor disorders. It can be a decrease in desire, a difficulty in reaching orgasm and, for men, disorders of erection or ejaculation. ${ }^{16}$ These sexual problems can be related to age (as for PD, the risk of developing erectile dysfunction increases after age 50) or to the disease itself. Indeed, dopamine plays a major role in libido and the occurrence of erection. As a result, the decline in dopamine production suffered by patients with PD may be associated with deterioration in their sex lives, ${ }^{20}$ but the motor symptoms of PD like tremors, hypertonia or akinesia (rarefaction and slowing of movements) are not likely to promote a satisfied sexuality. Psychological causes (depression and loss of self-esteem) have undoubtedly a negative effect on libido. Sexual desire also disappears because the sexual function is disrupted by disappointment, frustration, and anxiety/ depression, all main sources of mental health stress that turn off the libido as well sexual performances. Further, the direct and indirect effects of the disease such as loss of sexual desire does not arise of a simple decline in sexual motivation due to age or PD, it may be also related to medications.

\section{Impact of the treatment against PD}

Side effects of dopamine agonists: Although the cause remains unknown, several pathological processes and central factors such as protein aggregation, mitochondrial dysfunction, iron accumulation, neuroinflammation, and oxidative stress have been reported. Current treatment is primarily symptomatic using anti-Parkinson drugs namely levodopa, carbidopa, DA agonists, monoamine oxidase type B inhibitors and anticholinergics to replace DA. ${ }^{3}$ Many patients receiving DA agonist treatment for the severe neurological conditions of PD manifest uncontrollable sexual desire. ${ }^{21}$ Effectively, some anti-Parkinson treatments can alter the control of impulses in the brain leading thus to dramatic consequences like sexual assault of partner, family members, or carers. ${ }^{22}$ Recent studies showed that $15 \%$ of patients receiving a dopaminergic agonist exhibited an impulse control problem like hypersexuality, gambling, compulsive shopping, compulsive eating, or compulsive hobbyism, but this figure is underestimated and is probably around $20 \% .^{22}$

The occurrence of such side effects is closely related to the nature of PD: the progressive loss of the neurons responsible for the production of dopamine in the nigrostriatal system. ${ }^{1}$ The resulting drop of DA level in this brain region is compensate with two kind of treatments: bringing L-dopa, a mixed solution of dopamine in the central nervous system, or administrating dopaminergic agonists, molecules whose structure is close to that of dopamine. ${ }^{12}$ The effect of the latter is similar to that of L-dopa but their duration of action is longer. Moreover, the risk of dyskinesias is less, which justify their prescription in first intention.

Mechanisms of action: Each DA receptor is implicated in a wide range of physiological functions. Five DA receptors have been cloned. D1-like receptors (D1 and D5) are positively coupled to adenylate cyclase, and D2-like receptors (D2, D3 and D4) are negatively or not coupled to this enzyme. ${ }^{19}$ The main targets of the various dopaminergic agonists used in the treatment of Parkinson's disease are the dopamine receptors (D2 and D3) located in different areas of the brain. D2 receptors are numerous in structures involved in motricity, whereas D3 are also expressed in other regions, in particular the limbic system..$^{18}$ But the latter plays an important role in emotions and pleasure. ${ }^{19}$ Thus, the affinity of an agonist to bind D3 instead of D2 represents a greater risk of having impulse control disorder. ${ }^{18}$ D2 receptors have also been found to be particularly abundant in the dorsomedian and the dorsolateral nucleus, which innervates the bulbospongiosus and ischiocavernosus striated muscles, involved in penile rigidity in the rat..$^{23}$

Some neuroleptics have the ability to block D2 receptors in the anterior pituitary, and correlated to erectile dysfunction. ${ }^{24}$ Many others psychoactive substances (heroin, cocaine, cannabis, alcohol) can stimulated the reward system provoking an increasing release of DA. Impulse control problems have been associated to an excessive stimulation by the agonists of the D3 receptors, which may stop inhibiting mechanisms behind compulsive behaviors whilst stimulating reward system circuitry. Scientific research on active ingredients blocking D3 receptors or targeting specifically D2 should get more attention because their identification can improve drug manufacturing.

\section{Main sexual disorders associated to PD}

Erectile disorders: Most men with PD consider erectile dysfunction (ED) to be the most distressing of their various disabilities imposed by the disease. ${ }^{25} \mathrm{~A}$ total of $60 \%$ of men with PD reported ED, as compared with $37.5 \%$ in age-matched controls. ${ }^{26,27}$ Many males were also unable to ejaculate and to achieve an orgasm. ${ }^{10}$ Recent efforts to understand the physiological basis underlying ED in PD have evidenced an unrecognized high prevalence of testosterone deficiency in elderly male patients with PD, similar to that found in the general population. Testosterone deficiency is also a well-documented cause of decreased libido, erectile dysfunction and decreased work performance. ${ }^{28}$ Further erectile function is closely related to sexual motivation during normal intercourse and sexual motivation is partially under the control of dopaminergic system. ${ }^{29}$ With regard to the neurodegenerative nature of PD on this system, we can easily understand the occurrence of ED in PD.

Hypersexuality: Hypersexuality (HS) is usually considered to constitute a marked increase in sexual interest, arousal, and behavior, which has adverse consequences for the patient and their partner or carers, and is out of keeping with premorbid personality. It is often characterized by a preoccupation with sexual thoughts, frequent demands, and desire for sexual practice that might be quite different from those previously engaged in, and currently, habitual use of sex lines and Internet pornography or contact with sex workers. ${ }^{30,31}$ HS is often a consequence of dopaminergic dysregulation associated to higher doses of DA treatment.

Clinical and neuropsychological features of PD cases of patients with HS revealed that some of them developed paraphilias; described a completely new interest in masochistic sex; admitted to indecently exposing them self on several occasions; or drilled holes in the bathroom walls of their house to watch partner undress, or accused of sexually assaulting daughter by inappropriate physical contact. The behaviors led to the breakup of the relationships with partners in the majority of the cases. ${ }^{22}$

\section{Treatments of sexual disorders associated to PD}

Treatments of erectile dysfunction: $\mathrm{ED}$ is the only SD with evidence-based drug treatment available. ${ }^{32}$ Sildenafil is an effective treatment for ED in men with several neurological disorders, also PD. ${ }^{33,34}$ Its efficacy in PD patients with ED and depression was reported to be $85 \% .{ }^{33}$ Symptoms of Parkinson's disease and decreased libido in the non-depressed patient can be treated in different ways. Either by an L-Dopa treatment that will restore the dopamine level and relieve mo- 
tor symptoms or by using type 5 phosphodiesterase inhibitors, such as Cialis, Levitra, or Viagra, which are also useful against erectile dysfunction. Studies in humans have shown some effect of amphetamine $^{35}$ and yohimbine ${ }^{36}$ both of which are known to be dopaminergic, in the treatment of erectile dysfunction. Treatment with apomorphine sublingually is another therapeutic option for PD patients with ED. The action is through a dopaminergic effect in the hypothalamus. Doses of 2-4mg have been recommended, with the erection occurring within 10-25minutes. ${ }^{10}$

Treatments of hypersexuality: Hypersexuality requires an adaptation of the prescribed dopaminergic treatment to the patient. ${ }^{10}$ Introduction of an atypical neuroleptic treatment, or even antiandrogenic should reduced or even stopped HS. However this introduction will slightly conduce to motor function degradation. DA agonist could also be replaced by an anticholinergic, an MAO-B or an atypical neuroleptic at low dose. Moreover, Deep Brain Stimulation of the subthalamic nucleus has also demonstrated positive influence on sexual well being. ${ }^{37}$

\section{Natural products used against PD and its complica- tions}

Several pathological processes and central factors such as protein aggregation, mitochondrial dysfunction, iron accumulation, neuroinflammation and oxidative stress have been reported as the possible causes of PD. ${ }^{38}$ Current treatment is primarily symptomatic using anti-Parkinson drugs namely levodopa, carbidopa, dopamine (DA) agonists, monoamine oxidase type $\mathrm{B}$ inhibitors and anticholinergics to replace DA. When drug therapy is not satisfactory, surgical treatments are recommended. Unfortunately, the existing conventional strategies against PD are with numerous side effects, and possess an economic burden. Therefore, novel therapeutic approaches which can regulate pathways leading to neuronal death and dysfunction are needed.
For many years, nature has been providing the primary resource for the discovery of potential therapeutic agents. Remarkably, many natural products from medicinal plants, fruits, and vegetables have been shown to be good anti-Parkinson agents. ${ }^{3}$ Since they possess neuroprotective properties not only due to their well-recognized antioxidative and anti-inflammatory activities but also their inhibitory roles on iron accumulation, protein misfolding and maintenance of proteasomal degradation as well as mitochondrial homeostasis. Effectively, some natural remedies are specifically sought after for their neuroprotective action and can improve the therapeutic effects of traditional therapies. Among the most effective natural treatments to fight Parkinson's disease, there are dietary supplements and herbal remedies.

Vitamin D: Essential to prevent osteoporosis and maintain maximum effectiveness of the immune system, vitamin $\mathrm{D}$ is a micronutrient also fundamental to the brain. Several studies have shown not only that low levels of vitamin D are associated with an increased risk of neurodegenerative diseases, but also that taking vitamin D supplements helps to contain, and may even prevent, Parkinson's disease.

NADH: The dinucleotide nicotinamide adenine (NADH) also helps to fight against the manifestations of PD; it is a coenzyme involved in the energy production cycle and able to stimulate the synthesis of dopamine. The NADH dosage is normally 5 milligrams per day.

The most effective herbal remedies for $P D$ and related sexual dysfunctions: The variety of neuroprotective mechanisms of natural plant extracts allowed researchers to target PD progression in different pathological stages through multiple pathways. Interestingly, various plants extracts that have been investigated in preclinical trials for their neuroprotective effects against neurotoxicity induced by PD, also demonstrated aphrodisiac or an aphrodisiac properties in normal condition (Table 1). However the both, neuroprotective and aphrodisiac/an aphrodisiac properties, have never been tested together on the same model of PD.

Table I Potential herbal remedies against Parkinson's disease related sexual disorders

\begin{tabular}{|c|c|c|c|c|c|}
\hline Plants & $\begin{array}{l}\text { Common } \\
\text { name }\end{array}$ & Therapeutic activity on PD & Model & $\begin{array}{l}\text { Benefits for sexual } \\
\text { function }\end{array}$ & Studies \\
\hline $\begin{array}{l}\text { Mucuna } \\
\text { pruriens }\end{array}$ & Velvet bean & $\begin{array}{l}\text { Natural source of levodopa, improved } \\
\text { climbing behaviour and restored damaged } \\
\text { mitochondria }\end{array}$ & $\begin{array}{l}\text { Mutant model of Drosophilia } \\
\text { melanogaster; MPTP induced } \\
\text { neurotoxicity }\end{array}$ & $\begin{array}{l}\text { Aphrodisiac, mood and } \\
\text { libido enhancer, reduce } \\
\text { prolactin, enhance } \\
\text { testosterone }\end{array}$ & $38,39,47$ \\
\hline $\begin{array}{l}\text { Curcuma } \\
\text { longa }\end{array}$ & Curcumin & $\begin{array}{l}\text { Reduced depletion of dopamine, reversal of } \\
\text { glial fibrillary acidic protein (produced by } \\
\text { astrocytes during degeneration) and reduced } \\
\text { pro-inflammatory cytokines; reduced the iron } \\
\text { chelation in the dopaminergic neurons. }\end{array}$ & $\begin{array}{l}\text { MPTP induced model; } \\
\text { 6-OHDA mouse model of PD }\end{array}$ & Aphrodisiac & 48,49 \\
\hline $\begin{array}{l}\text { Albizia } \\
\text { adianthifolia }\end{array}$ & $\begin{array}{l}\text { Sene } \\
\text { (Ewondo- } \\
\text { Cameroon) }\end{array}$ & $\begin{array}{l}\text { Attenuates 6-OHDA induced anxiety, } \\
\text { depression, and oxidative stress in rat } \\
\text { amygdala, cognitive-enhancing effects }\end{array}$ & $\begin{array}{l}\text { 6-OHDA-lesioned rat model } \\
\text { of PD }\end{array}$ & $\begin{array}{l}\text { Anaphrodisiac endowed } \\
\text { with estrogenic } \\
\text { properties }\end{array}$ & 50 \\
\hline $\begin{array}{l}\text { Pausinystalia } \\
\text { yohimbe }\end{array}$ & Yohimbe & $\begin{array}{l}\text { Low affinity to some of the dopamine } \\
\text { receptors, Antidepressant; Patients } \\
\text { demonstrated a vulnerability to yohimbine- } \\
\text { induced somatic symptoms (Panick attack) }\end{array}$ & $\begin{array}{l}\text { Parkinsonian patients; chronic } \\
\text { mild stress rat model, }\end{array}$ & $\begin{array}{l}\text { Most widely recognized } \\
\text { natural aphrodisiac, } \\
\text { inhibit testicular lipid } \\
\text { peroxidation, increase } \\
\text { arterial blood pressure }\end{array}$ & $44,51,52$ \\
\hline $\begin{array}{l}\text { Carthamus } \\
\text { tinctorius. } L\end{array}$ & Safflower & $\begin{array}{l}\text { Reversed the decreased protein expression of } \\
\text { tyrosine hydroxylase, dopamine transporter } \\
\text { and DJ-I and increased the levels of } \\
\text { dopamine and its metabolite }\end{array}$ & Rotenone-Induced Rat Model & $\begin{array}{l}\text { Very effective } \\
\text { aphrodisiac, Improves } \\
\text { sexual vigor and thickens } \\
\text { semen. }\end{array}$ & 53 \\
\hline
\end{tabular}


Table Continued...

\begin{tabular}{|c|c|c|c|c|c|}
\hline Plants & $\begin{array}{l}\text { Common } \\
\text { name }\end{array}$ & Therapeutic activity on PD & Model & $\begin{array}{l}\text { Benefits for sexual } \\
\text { function }\end{array}$ & Studies \\
\hline $\begin{array}{l}\text { Humulus } \\
\text { japonicus }\end{array}$ & $\begin{array}{l}\text { (Japanese) } \\
\text { hops }\end{array}$ & $\begin{array}{l}\text { (in vitro) increased glutathione levels and } \\
\text { decreased phosphorylation of ERKI/2 in SH- } \\
\text { SY5Y cells exposed to 6-OHDA } \\
\text { (in vivo) improved the motor dysfunction and } \\
\text { notably reduced dopaminergic cell death and } \\
\text { fiber loss in the SNc and striatum caused by } \\
6-\mathrm{OHDA}\end{array}$ & $\begin{array}{l}\text { In vitro and in vivo } \\
\text { 6-hydroxydopamine (6- } \\
\text { OHDA) models }\end{array}$ & $\begin{array}{l}\text { Possessestrogenic and } \\
\text { vasodilatory properties, } \\
\text { treat anxiety and } \\
\text { insomnia }\end{array}$ & 54 \\
\hline
\end{tabular}

6-OHDA, 6-hydroxydopamine; SNc, substantia nigra pars compacta

Mucuna pruriensis a natural source of levodopa, the most commonly used medication to cure PD. It is also an established herbal drug used for the management of male infertility, nervous disorders, and also as an aphrodisiac ${ }^{39} \mathrm{M}$. pruriens has been used traditionally as an aphrodisiac for both men and women. ${ }^{40}$ One of the scientific reasons behind the effectiveness of this herb for this purpose is due to its activity on hormonal profile. $M$. pruriens reduces excessive prolactin and increases testosterone in the body. Prolactin tends to counteract testosterone in the body, thus reducing sexual interest.

Ginkgo biloba therapeutic effects on cerebral blood circulation and cognitive functions are now known and recognized. ${ }^{41} G$. giloba extract contains flavonoid glycosides, mainly composed of kaempferol, quercetin glucorhamnoside esters, and terpenes of ginkgolides and bilobalides. These ingredients have been suggested to have the ability to inhibit MAO enzyme and uptake of certain neurotransmitters such as noradrenaline and serotonin in the central nervous system. ${ }^{42} \mathrm{~A}$ recent meta-analysis of 28 clinical studies with Ginkgo has found no significant effect on cognitive function. ${ }^{41}$ Further the herb Ginkgo biloba has long been considered as one of the most potent aphrodisiacs for men. Ginkgo extracts have been suggested to improve sexual function by improving the blood flow to the brain as well as to the genital organs. These extracts have also been suggested to increase NO bioavailability, which may have positive impact on sexual function. ${ }^{43}$

Yohimbine is a natural tryptamine alkaloid, which can be extracted from the bark of Pausinystalia yohimbe, a tree from Africa and Asia origin. Yohimbe bark extract is traditionally used in Africa as an aphrodisiac. ${ }^{44}$ Yohimbine has high affinity to human alpha-2 adrenoceptors, moderate affinity to alpha- 1 adrenoceptors, and low affinity to some of the serotonin and dopamine receptors in the central and peripheral nervous systems. ${ }^{45}$ Alpha- 2 adrenoceptors mediate erection-inhibiting impulses in the central nervous system and Yohimbine is generally believed to enhance central sexual impulse by blocking the alpha-2 adrenoceptors in the locus coeruleus in the brain. ${ }^{46}$

Bacopa monnieri also called 'Brahmi' in India is a brain tonic mainly used to improve memory and concentration, and in general to support cognitive function. Animal model studies have shown that Bacopa extracts help prevent degeneration of dopaminergic neurons and may represent good supplementation in the treatment of Parkinson's disease. B. Monnieri is also considered in certain part of Asia, as brain tonic, aphrodisiac, memory booster, and tonic for many ailments.

\section{Conclusion}

Sexuality is a basic human right and essential part of healthy life. Sexual disorders, particularly erectile dysfunction and Hypersexuality, are significantly frequent among patients with $\mathrm{PD}$, but they remains underestimated and commonly neglected, despite their considerable impact on the deterioration of the life quality of patients with PD. However, Hypersexuality is more and more recognized and it has been evidenced that it is often associated with PD treatment. Until now, there is no effective cure for PD, and this review propose to search for neuroprotective strategies to stop or slow the disease progression taking into consideration the importance of the development of safe sexual medicine based on natural herbs. Natural remedies may constitute an alternative or complementary medicine to avoid detrimental side effects like sexual disorders commonly associated to PD treatment. Thus, we have described the process by which PD and its treatment have an impact on the sexual functioning andwell being of patients, their partners, and their relationships.

The variety of neuroprotective and aphrodisiac or an aphrodisiac mechanisms of natural plant extracts may allow researchers to target PD progression in different pathological stages and may be through multiple pathways exemplarily by alleviating neuro degeneration and erectile dysfunction or by exhibiting antidepressant activity. Nevertheless, further investigations are required to translate these mechanisms into safe and effective treatments for PD and its related symptoms.

\section{Acknowledgements}

Authors would like to acknowledge the contribution of the $\mathrm{PhD}$ students Mbolang Nguegan Lohik and Femoe Membe Ulrich from the Laboratory of Animal Physiology, University of Yaounde I in Cameroon for their help with the systematic literature review.

\section{Conflict of interest}

The author declares no conflict of interest.

\section{References}

1. Dauer W, Przedborski S. Parkinson's disease: mechanisms and models. Neuron. 2003;39(6):889-909.

2. Reglodi D, Renaud J, Tamas A, et al. Novel tactics for neuroprotection in Parkinson's disease: Role of antibiotics, polyphenols and neuropeptides. Prog Neurobiol. 2015;155:120-148.

3. Solayman M, Islam MA, Alam F, et al. Natural products combating against neurodegeneration: Parkinson's disease. Curr Drug Metab. 2016;18(1):50-61.

4. Kanthasamy A, Huajun J, Suneet M, et al. Novel cell death signaling pathways in neurotoxicity models of dopaminergic degeneration: Relevance to oxidative stress and neuroinflammation in Parkinson's disease. Neurotoxicology. 2010;31(5):555-561.

5. Miller IN, Cronin Golomb A. Gender differences in Parkinson's disease: clinical characteristics and cognition. Mov Disord. 2010;25(16):26952703 . 
6. Prakash KM, Nadkarni NV, Lye WK, et al. The impact of non-motor symptoms on the quality of life of Parkinson's disease patients: a longitudinal study. Eur J Neurol. 2016;23(5):854-860.

7. Micieli G, Tosi P, Marcheselli S, et al. Autonomic dysfunction in Parkinson's disease. Neurol Sci. 2003;24(1):S32-34.

8. Chaudhuri KR, Healy DG, Schapira AH. Non-motor symptoms of Parkinson's disease: diagnosis and management. Lancet Neurol. 2006;5(3):235-245

9. Truong DD, Bhidayasiri R, Wolters E. Management of non-motor symptoms in advanced Parkinson disease. J Neurol Sci. 2008;266(1-2):216228

10. Bronner G, Vodusek DB. Management of sexual dysfunction in Parkinson's disease. Ther Adv Neurol Disord. 2011;4(6):375-383.

11. Kakkar AK, Dahiya N. Management of Parkinson's disease: current and future pharmacotherapy. Eur J Pharmacol. 2015;750:74-81.

12. Pathak Gandhi N, Vaidya AD. Management of Parkinson's disease in ayurveda: medicinal plants and adjuvant measures. J Ethnopharmacol. 2016;197:46-51.

13. Merims D, Giladi N. Dopamine dysregulation syndrome, addiction and behavioral changes in Parkinson's disease. Parkinsonism Relat Disord. 2008;14(4):273-280.

14. Bhattacharyya KB, Rosa Grilo M. Sexual dysfunctions in Parkinson's disease: an underrated problem in a much discussed disorder. Int Rev Neurobiol. 2017;134:859-876.

15. Hand A, Gray WK, Chandler BJ, et al. Sexual and relationship dysfunction in people with Parkinson's disease. Parkinsonism Relat Disord. 2010;16(3):172-176.

16. Ferrucci R, Panzeri M, Ronconi L, et al. Abnormal sexuality in Parkinson's disease: fact or fancy? J Neurol Sci. 2016;369:5-10

17. Giovannoni G, O’Sullivan JD, Turner K, et al. Hedonistic homeostatic dysregulation in patients with Parkinson's disease on dopamine replacement therapies. J Neurol Neurosurg Psychiatry. 2000;68(4):423-428.

18. Domino EF, Sheng J. Relative potency and Efficacy of some dopamine agonists with varying selectivities for D1 and D2 receptors in MPTP-induced hemiparkinsonian monkeys. $J$ Pharmacol Exp Ther. 1993;265(3):1387-1391

19. Giuliano F, Allard J. Dopamine and Male Sexual Function. Eur Urol. 2001;40(6):601-608.

20. Courty E, Durif F, Zenut M, et al. Psychiatric and sexual disorders induced by apomorphine in Parkinson's disease. Clin Neuropharmacol. 1997;20(2):140-147.

21. Callesen MB, Scheel Kreuger J, Kringelbach ML, et al. A systematic review of impulse control disorders in Parkinson's disease. J Parkinsons Dis. 2013;3(2):105-138.

22. Codling D, Shaw P, David AS. Hypersexuality in Parkinson's disease: systematic review and report of 7 new cases. Mov Dis Clin Prac. $2015 ; 2(1): 116-126$

23. Van Dijken H, Dijk J, Voom P, et al. Localization of dopamine D2 receptor in rat spinal cord identified with immunocytochemistry and in situ hybridization. Eur J Neurosci. 1996;8(3):621-628.

24. Gooren L. Preliminary evidence that not prolactin itself, but the underlying dopaminergic dysregulation causes male sexual dysfunction in the cases of hyperprolactinemia. Int Acad Sex Res, Amsterdam, Netherlands: Springer; 1986

25. Basson R. Sexuality and Parkinson's disease. Parkinsonism Relat Disord. 1996;2(4):177-185.
26. Singer C, Weiner WJ, Sanchez Ramos IR, et al. Sexual function in patients with Parkinson's disease. J Neurol Neurosurg Psychiatry. 1991;54(10):942.

27. Sakakibara R, Shinotoh H, Uchiyama T, et al. Questionnaire-based assessment of pelvic organ dysfunction in Parkinson's disease. Auton Neurosci. 2001;92(1-2):76-85.

28. Okun MS, McDonald WM, DeLong MR. Refractory nonmotor symptoms in male patients with Parkinson disease due to testosterone deficiency. Arch Neurol. 2002;59(5):807-811.

29. Heaton JP. Central neuropharmacological agents and mechanisms in erectile dysfunction: The role of dopamine. Neurosci Biobehav Res. 2000;24(5):561-569.

30. de Chazeron I, Pereira B, Llorca PM, et al. Assessing hypersexuality in Parkinson's disease: validation of a screening instrument. Parkinsonism Relat Disord. 2012;18(2):37.

31. Weintraub D, Koester J, Poteza MN, et al. Impluse control disorders in Parkinson disease: a cross-sectional study of 3090 patients. Arch Neurol. 2010;67(5):589-595

32. Zesiewicz TA, Sullivan KL, Arnulf I, et al. Practice Parameter: treatment of nonmotor symptoms of Parkinson disease: report of the Quality Standards Subcommittee of the American Academy of Neurology. Neurol. 2010;74(11):924-931.

33. Raffaele R, Vecchio I, Giammusso B, et al. Efficacy and safety of fixed-dose oral sildenafil in the treatment of sexual dysfunction in depressed patients with idiopathic Parkinson's disease. Eur Urol. 2012;41(4):382386.

34. Hussain IF, Brady CM, Swinn MJ, et al. Treatment of erectile dysfunction with sildenafil citrate (Viagra) in Parkinsonism due to Parkinson's disease or multiple system atrophy with observation on orthostatic hypotension. J Neurol Neurosurg Psychiatry. 2001;71(3):371-374.

35. Bartlik B, Kaplan P, Kaplan HS. Psychostimulants apparently reverse sexual dysfunction secondary to selective serotonin re-uptake inhibitors. J Sex Marital Ther. 1995;21(4):264-271.

36. Ernst E, Pittler MH. Yohimbine for erectile dysfunction: a systematic review and meta-analysis of randomized clinical trials. $J$ Urol. 1998;159(2):433-436

37. Castelli L, Perozzo P, Genesia ML, et al. Sexual well being in Parkinsonian patients after deep brain stimulation of the subthalamic nucleus. $J$ Neurol Neurosurg Psychiatry. 2004;75(9):1260-1264.

38. Wang ZY, Liu JY, Yang CB, et al. Neuroprotective natural products for the treatment of Parkinson's disease by targeting the autophagy-lysosome pathway: a systematic review. Phytother Res. 2017;1(8):1119-1127.

39. Lampariello LR, Cortelazzo A, Guerranti R, et al. The Magic velvet bean of mucuna pruriens. J Tradit Complement Med. 2012;2(4):331-339.

40. Sathiyanarayanan L, Arulmozhi S. Mucuna pruriens: A comprehensive review. Pharmacognosy Rev. 2007;1(1):157-162.

41. Laws KR, Sweetnam H, Kondel TK. Is Ginkgo biloba a cognitive enhancer in healthy individuals? A meta-analysis. Hum Psychopharmacol. 2012;27(6):527-533.

42. Fehske CJ, Leuner K, Müller WE. Ginkgo biloba extract (EGb761) influences monoaminergic neurotransmission via inhibition of NE uptake, but not MAO activity after chronic treatment. Pharmacol Res. 2009;60(1):68-73.

43. Schmitt CA, Dirsch VM. Modulation of endothelial nitric oxide by plant-derived products. Nitric Oxide. 2009;21(2):77-91.

44. Kameni PM, Dzeufiet DP, Bilanda DC, et al. Protective effects of Nymphaea lotus Linn. (Nymphaeaceae) aqueous extract against chronic unpredictable mild stress induced testicular lipid per oxidation. Asian $J$ Biomed Pharm Sci. 2016;6(54):1-6. 
45. Goldberg MR, Robertson D. Yohimbine: a pharmacological probe for study of the $\alpha 2$-adrenoreceptor. Pharmacol Rev. 1983;35(3):143-180.

46. Chang AYW, Huang CM, Chan JYH, et al. Involvement of noradrenergic innervation from locus coeruleus to hippocampal formation in negative feedback regulation of penile erection in the rat. Hippocampus. 2001;11(6):783-792.

47. Poddighe S, De Rose F, Marotta R, et al. Mucuna pruriens (Velvet bean) rescues motor, olfactory, mitochondrial and synaptic impairment in PINK1B9 Drosophila melanogaster genetic model of Parkinson's disease. PLoS One. 2014;9(10):e110802.

48. Pandey N, Galvin JE. Curcumin prevents aggregation of alpha-synuclein. Soc Neurosci. 2005;31 abs 1007.9.

49. Mythri BR, Harish G, Raghunath N, et al. Therapeutic Potential of Polyphenols in Parkinson's Disease. Intech web; 2011. p. 116-150.

50. Beppe JG, Dongmo AB, Foyet HS, et al. The aqueous extract of Albizia adianthifolia leaves attenuates 6-hydroxydopamine induced anxiety, depression and oxidative stress in rat amygdala. BMC Complement Altern Med. 2015;15:374.
51. Corazza O, Martinotti G, Santacroce R, et al. Sexual enhancement products for sale online: raising awareness of the psychoactive effects of yohimbine, maca, horny goat weed, and Ginkgo biloba. Biomed Res Int. 2014;2014:841798.

52. Richard IH, Szegethy E, Lichter D, et al. Parkinson's disease: a preliminary study of yohimbine challenge in patients with anxiety. Clin Neuropharmacol. 1999;22(3):172-175.

53. Ablat N, Lv D, Ren R, et al. Neuroprotective effects of a standardized flavonoid extract from safflower against a rotenone-induced rat model of Parkinson's disease. Molecules. 2016;21(9).

54. Ryu YK, Kang Y, Go J, et al. Humulus japonicus prevents dopaminergic neuron death in 6-hydroxydopamine-induced models of Parkinson's disease. J Med Food. 2017;20(2):116-123. 